\title{
Maternal outcome in pregnancy with thrombocytopenia
}

\author{
Manthan Sojitra*, Sushma R. Shah, Ami V. Mehta, Payal P. Panchal, Ronak Bhankhar
}

Department of Obstetrics and Gynecology, SVPIMSR, Ahmedabad, Gujarat, India

Received: 02 May 2020

Accepted: 30 May 2020

\section{*Correspondence:}

Dr. Manthan Sojitra,

E-mail: manthansojitra@gmail.com

Copyright: () the author(s), publisher and licensee Medip Academy. This is an open-access article distributed under the terms of the Creative Commons Attribution Non-Commercial License, which permits unrestricted non-commercial use, distribution, and reproduction in any medium, provided the original work is properly cited.

\section{ABSTRACT}

Background: Thrombocytopenia is second most common haematological abnormality in pregnancy after anemia. The aim of this study was to find out the prevalence, causative factor of thrombocytopenia and to observe the obstetrics outcome of pregnancies complicated with thrombocytopenia.

Methods: This is prospective study of maternal outcome in pregnancy with thrombocytopenia carried out at tertiary care center from February 2019 to January 2020. Out of 350 antenatal screened women, 25 women who were diagnosed with thrombocytopenia, were included in the study.

Results: The incidence of maternal thrombocytopenia in this study was $7.1 \% .60 \%$ of the women had mild thrombocytopenia while $24 \%$ and $16 \%$ of women were moderate and severe thrombocytopenic respectively. Amongst 25 thrombocytopenic women $68 \%$ had gestational thrombocytopenia, $24 \%$ had gestational hypertensive disorder,4\% had HELLP syndrome, $4 \%$ had immune thrombocytopenic purpura. $60 \%$ were delivered vaginally and $40 \%$ were delivered by LSCS. The most common indication of LSCS was acute fetal distress $(40 \%)$ followed by failed induction $(30 \%)$, breech $(10 \%)$, and the rest $(20 \%)$ for other obstetrical indications. The most common indication for induction was pre-eclampsia followed by IUGR, and post-date.

Conclusions: In pregnancy with thrombocytopenia, gestational thrombocytopenia is the commonest and benign condition which does not alter the obstetrical management. Still a vigil 4 should be kept on maternal platelet count in antenatal period to prevent unfavorable outcome in serious conditions that may require specific and urgent management (HELLP syndrome, severe pre-eclampsia, ITP).

Keywords: Gestational hypertension, Maternal outcome, Pregnancy, Thrombocytopenia

\section{INTRODUCTION}

Pregnancy is a physiological state which is associated with adaptations in metabolic and biochemical processes. Normal serum platelet count in pregnancy is 1.5-4 lakh/ $\mu 1$. Pregnancy causes a physiological fall in the platelet count. Low platelet counts can be due to an increase in consumption or destruction or rarely due to less production of platelets, due to haemodilution of plasma volume platelet count decrease by approximately $6-7 \%$ during $3^{\text {rd }}$ trimester. $^{1}$

Thrombocytopenia is second most common haematological abnormality in pregnancy after anemia. ${ }^{2}$
The overall incidence of thrombocytopenia in pregnancy is approximately $8-10 \%$ but when patients with preexisting medical conditions are excluded, then the incidence drops to $5.1 \% .^{2} \mathrm{~A}$ drop in platelet count below $150,000 / \mu \mathrm{l}$ is defined as thrombocytopenia. Thrombocytopenia may be mild - 100,000-150,000/ 1 , moderate - 50,000-100,000/ $\mu \mathrm{l}$, severe - 50,000/ $\mathrm{L} .^{3}$ Any pregnant patient with platelet count below $100,000 / \mu \mathrm{L}$ requires further clinical and laboratory assessment.

Here are diverse etiologies of thrombocytopenia in pregnancy out of which some are unique to pregnancy. ${ }^{4}$ Approximately $75 \%$ of these cases are due to gestational thrombocytopenia; $15-20 \%$ can be due to hypertensive 
disorders; $3-4 \%$ to an immune process and the remaining $1-2 \%$ are made up of rare constitutional thrombocytopenia, infections and hematological malignancies. Thrombocytopenia in the obstetric patient may be due to benign disorders such as incidental gestational thrombocytopenia to life-threatening syndromes such as the 'hemolysis, elevated liver enzymes, low platelets' syndrome (HELLP). ${ }^{1}$

Table 1: Etiology of thrombocytopenia in pregnancy. ${ }^{4}$

\begin{tabular}{|lll|}
\hline $\begin{array}{l}\text { Isolated } \\
\text { thrombocytopenia }\end{array}$ & $\begin{array}{l}\text { Pregnancy specific } \\
\text { Thrombocytopenia } \\
(70-80 \%)\end{array}$ & $\begin{array}{l}\text { Not pregnancy specific } \\
\text { Primary ITP }(1-4 \%) \text { secondary ITP }(<1 \%)^{*} \text { drug induced } \\
\text { thrombocytopenia** congenital thrombocytopenia** type 2B } \\
\text { von willebrand disease** }\end{array}$ \\
\hline $\begin{array}{l}\text { Thrombocytopenia } \\
\text { associated with } \\
\text { systemic disorders }\end{array}$ & $\begin{array}{l}\text { Severe preeclampsia }(15- \\
20 \%) \text { HELLP syndrome } \\
(<1 \%) \text { acute fatty liver } \\
\text { disease of pregnancy }(<1 \%)\end{array}$ & $\begin{array}{l}\text { Thrombotic thrombocytopenic purpura /hemolytic uremic } \\
\text { syndrome** systemic lupus erythromatosus** anti-phospholipid } \\
\text { antibody syndrome** viral infections** bone marrow } \\
\text { disorders** nutritional deficiency** thyroid disorders** splenic } \\
\text { sequestration (liver diseases, portal vein thrombosis etc.)** }\end{array}$ \\
\hline
\end{tabular}

Most of the cases of thrombocytopenia are mild and have no significant effect on mother but in those cases where it is a part of a complex clinical disorder like HELLP syndrome it can be profound and can lead to lifethreatening results.

Bleeding during surgery is uncommon unless the platelet counts are less than 50,000/microliter. Clinically significant spontaneous bleeding occurs when platelet counts fall below $10,000 / \mu \mathrm{L}$. Pregnant women with thrombocytopenia have high risk of bleeding during and after childbirth especially if caesarean section, episiotomy procedure, perineal tear or other surgical intervention has done during pregnancy, labor, and puerperium. Such bleeding complications are more likely when platelet count is less than $50,000 / \mu \mathrm{L}$.

The aim of this study was to find out the prevalence, causative factor of thrombocytopenia and to observe the obstetrics outcome of pregnancies complicated with thrombocytopenia.

\section{METHODS}

This is prospective study of maternal outcome in pregnancy with thrombocytopenia carried out at tertiary care center from February 2019 to January 2020. Out of 350 antenatal screened women, 25 women who were diagnosed with thrombocytopenia, were included in the study.

\section{Inclusion criteria}

- The indoor patients who were diagnosed of thrombocytopenia, on the basis of blood investigations and clinical picture and delivered at authors tertiary care center and who agreed to give consent, were included.

\section{Exclusion criteria}

- Patient unwilling to give informed consent were excluded.

Antenatal women were diagnosed with thrombocytopenia in the study in second and third trimester. Demographic features, detailed history, presenting complaints if any, findings of general, systemic and obstetrical examination including pelvic examination if required of all the patient were recorded. Baseline investigations was done. The detailed work-up of all cases was done to ascertain the cause of thrombocytopenia. History of petechiae, bruising, drug usage, viral infection, thrombocytopenia in previous pregnancy was taken.

Gestational age was established by menstrual history and clinical examination and confirmed by USG. All the cases were followed till delivery to record any complications like preterm labour, abruption, preeclampsia, any other morbidity and they were managed as multidisciplinary approach. Duration of pregnancy at the time of delivery, indication of induction and method and mode of delivery including indication for caesarean section were recorded. Progress of labor was monitored partographically. All women enrolled were followed up by estimation of platelet count on 10th days postpartum.

\section{RESULTS}

During study period from February 2019 to January 2020, 25 women were found having gestational thrombocytopenia.

Out of women having thrombocytopenia, 14 (56\%) were less than 25 years, $8(32 \%)$ were between 25 to 30 years and $3(12 \%)$ were more than 30 years of age (Table 2 ). 
Out of women having thrombocytopenia, $60 \%$ women were multigravida and $40 \%$ women were primigravida.

Table 2: Distribution of study group as per age.

\begin{tabular}{|ll|}
\hline Age group (years) & $\mathbf{n}(\%)$ \\
\hline$<25$ & $14(56 \%)$ \\
\hline $25-30$ & $8(32 \%)$ \\
\hline$>30$ & $3(12 \%)$ \\
\hline
\end{tabular}

Amongst thrombocytopenic women $68 \%$ had gestational thrombocytopenia, $24 \%$ had gestational hypertensive disorder, $4 \%$ had HELLP syndrome, $4 \%$ had immune thrombocytopenic purpura (Figure 1).

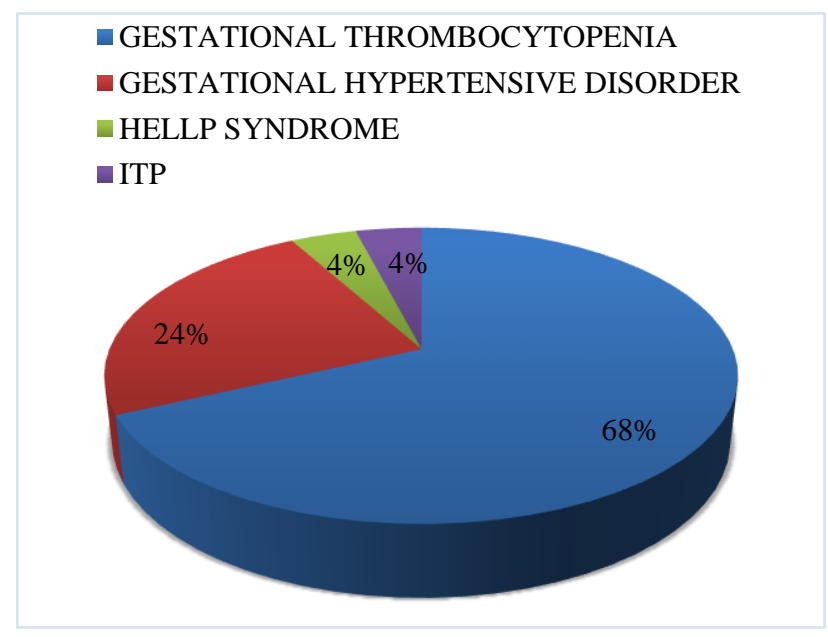

Figure 1: Etiology of thrombocytopenia in pregnancy.

Table 3: Distribution of study group as per mode of delivery.

\begin{tabular}{|llll|}
\hline $\begin{array}{l}\text { Mode of } \\
\text { delivery }\end{array}$ & $\begin{array}{l}\text { Total } \mathrm{n} \\
(\%)\end{array}$ & Preterm & Full-term \\
\hline $\begin{array}{l}\text { Vaginal } \\
\text { delivery }\end{array}$ & $15(60 \%)$ & $3(12 \%)$ & $12(48 \%)$ \\
\hline $\begin{array}{l}\text { Caesarean } \\
\text { section }\end{array}$ & $10(40 \%)$ & $4(16 \%)$ & $6(24 \%)$ \\
\hline Total & $25(100 \%)$ & $7(28 \%)$ & $18(72 \%)$ \\
\hline
\end{tabular}

Out of women having thrombocytopenia, $60 \%$ of the women had mild thrombocytopenia, $24 \%$ had moderate thrombocytopenia and $16 \%$ of women had severe thrombocytopenia.

Out of women having thrombocytopenia, $60 \%$ were delivered vaginally and $40 \%$ were delivered by LSCS. The most common indication of LSCS was acute fetal distress (40\%) followed by failed induction (30\%), breech $(10 \%)$, and the rest $(20 \%)$ for other obstetrical indications (Table 3).

Out of women having thrombocytopenia, $72 \%$ were delivered at term $(>=37$ weeks $)$ and remaining $28 \%$ were delivered before term $(<37$ weeks $)$.
Out of women having thrombocytopenia, $20 \%$ were required platelet transfusion and $80 \%$ did not required platelet transfusion.

There was no maternal mortality. All the patients discharged in a stable condition. Follow-up was arranged after 6 weeks. On follow-up, platelet count was repeated which is found to be normal in all the cases.

\section{DISCUSSION}

Most of the patients with mild thrombocytopenia do not need altered obstetrical management but at times severe thrombocytopenia, in life threatening conditions like HELLP syndrome, poses a great challenge to the treating obstetrician.

Table 4: Comparison of studies according to incidence of maternal thrombocytopenia.

\begin{tabular}{|c|c|}
\hline Study & Incidence \\
\hline Dwivedi et $\mathrm{al}^{6}$ & $8.17 \%$ \\
\hline Vyas et al $^{7}$ & $7.6 \%$ \\
\hline Burrows et al ${ }^{8}$ & $7.6 \%$ \\
\hline Singh et al ${ }^{9}$ & $8.8 \%$ \\
\hline Ajibola et al ${ }^{10}$ & $13.5 \%$ \\
\hline Onisai et al ${ }^{11}$ & $11.11 \%$ \\
\hline Brohi et al ${ }^{12}$ & $1.9 \%$ \\
\hline Lin et al ${ }^{13}$ & $4.3 \%$ \\
\hline Present study & $7.1 \%$ \\
\hline
\end{tabular}

In present study the incidence of maternal thrombocytopenia was $7.1 \%$ which was comparable to the studies by Dwivedi et al $(8.17 \%)$, Vyas et al $(7.60 \%)$ Burrows et al $(7.60 \%)$ and Singh et al $(8.80 \%){ }^{6-9}$ However, the incidence of thrombocytopenia was higher in the studies by Ajibola et al (13.50\%) and Onisai et al $(11.11 \%) .{ }^{10,11}$ Lower incidence was noted in the study of Brohi et al (1.90\%) and Lin et al (4.30\%) (Table 4). ${ }^{12,13}$

The mean age of patients in present study was 27.33 years. In a study by Suri et al, the mean age was 27 years. ${ }^{14}$ In study by Borna et al, Turgot et al, Jaleel et al mean age of patient was 28, 27.6 \pm 5.7 and 28.43 respectively. ${ }^{15-17}$ Where as in a study by Ruggri et al the mean age was higher i.e. $32.20 .^{18}$

Majority of the patients in present study were multigravida $60 \%$ followed by primigravida $40 \%$. This was in contrast with the study conducted by Janes SL et al, which showed its prevalence was more in primigravida (70\%) and in multigravida (30\%). ${ }^{19}$

In this study $60 \%$ women had mild thrombocytopenia. However, mild thrombocytopenia was noted in 54\% and $74.7 \%$ patients included in the study by Borna et al which is lower than this study and Singh et al respectively., 9 Singh et al reported a higher incidence of thrombocytopenia i.e. $74.4 \%$ as compare to this study. ${ }^{9}$ 
$24 \%$ patient had moderate thrombocytopenia which is similar to study conducted by Borna et al $30 \%$ whereas in study by Singh et al moderate thrombocytopenia was seen in less number of patient i.e. 17.9.\%.9,15 Severe thrombocytopenia was seen in $16 \%$ of patient, as in study of Borna et al and Singh et al severe thrombocytopenia was seen in $16 \%$ and $7.4 \%$ respectively (Table 5). ${ }^{9,15}$

\section{Table 5: Comparison of studies according to severity} of maternal thrombocytopenia.

\begin{tabular}{|llll|}
\hline Study & Mild & Moderate & Severe \\
\hline Singh et al & $74.7 \%$ & $17.9 \%$ & $7.4 \%$ \\
\hline Borna et al $^{15}$ & $54 \%$ & $30 \%$ & $16 \%$ \\
\hline Present study & $60 \%$ & $24 \%$ & $16 \%$ \\
\hline
\end{tabular}

In present study mean gestation age at delivery was 38 weeks. In a study conducted by Lin et al and Kasai et al the age was 39 weeks and 38 weeks respectively. ${ }^{13,20}$ Where as in the study by Bouzari et al the age was $35.83 \pm 3.61$ weeks which was lower than this study. ${ }^{21}$

Table 6: Distribution of subjects according to association with gestational hypertension.

\begin{tabular}{|ll|}
\hline Study & $\begin{array}{l}\text { Association with gestational } \\
\text { hypertension }\end{array}$ \\
\hline${\text { Vyas et } \mathrm{al}^{7}}^{7}$ & $22 \%$ \\
\hline${\text { Burrows et } \mathrm{al}^{3}}^{3}$ & $21 \%$ \\
\hline Singh et al & $24.2 \%$ \\
\hline Onisai et $\mathrm{al}^{11}$ & $21.15 \%$ \\
\hline${\text { Brohi et } \mathrm{al}^{12}}^{22}$ & $26.7 \%$ \\
\hline Parnas et $\mathrm{al}^{22}$ & $21.11 \%$ \\
\hline Present study & $24 \%$ \\
\hline
\end{tabular}

In the present study the association of thrombocytopenia with gestational hypertension was seen in $24 \%$ women, which was similar to the studies of Brohi et al (26.70\%), Singh et al $(24.20 \%)$, Vyas et al $(22 \%)$ Parnas et al $(21.11 \%)$ and Burrows et al (21\%) (Table 6). ${ }^{7,9,12,22}$

In the present study HELLP syndrome was seen in $4 \%$ of the thrombocytopenic women, in study by Vyas et al $4.08 \%$, Turgot et al $1.14 \%$ and Habas et al $0.37 \%$. $^{7,23,24}$ Whereas studies by Parnas et al and Onisai et al showed HELLP syndrome in $12.06 \%$ and $9.52 \%$ women respectively, which was higher than this study. ${ }^{11,22}$

In present study incidence of ITP was 4\% amongst pregnant thrombocytopenic women. In the study conducted by Burrows et al incidence was $3 \% .^{3}$ In the study conducted by Singh et al the incidence of ITP was $8.40 \% .^{9}$

In this study $60 \%$ of subjects had delivered vaginally and $40 \%$ patient delivered by LSCS which was similar to study by Singh et al (vaginally 64\% and LSCS 36\%) and Vyas et al (vaginally $63 \%$ and LSCS 37\%) and Ruggri et al (vaginally $80 \%$ and LSCS $20 \%$ ). ${ }^{7,18}$ Whereas the incidence of LSCS was higher in the studies conducted by Pafumi et al (55\%) and Yuce et al $(56 \%){ }^{25,26}$

In this study, platelet transfusion was required in $20 \%$ patients. In study conducted by Ajzenberg $\mathrm{N}$ et al, showed $22 \%$ needed treatment for thrombocytopenia out of which only $2 \%$ needed platelet transfusion. ${ }^{27}$

\section{CONCLUSION}

The normal range of platelet count in non-pregnant women is $1,50,000 / \mu \mathrm{L}$ to $4,00,000 / \mu \mathrm{L}$. It decreases in pregnancy $(2,15,000 / \mu \mathrm{L})$.

In this study the incidence of thrombocytopenia was $7.1 \%$. Gestational thrombocytopenia was the commonest cause with incidence of $68 \%$, followed by gestational hypertension 24\%, ITP $4 \%$ and HELLP syndrome $4 \%$.

Gestational thrombocytopenia is the commonest cause of thrombocytopenia and may not be related to adverse pregnancy outcome, thus can be treated as benign condition. Clinical assessment is the most important factor for evaluating a patient with thrombocytopenia. A detailed history including previous or current bleeding problem, family history, past obstetrics history, drug abuse and blood transfusion history is important.

A careful examination and simple laboratory test are needed so that a serious condition that may require specific and urgent management (examples HELLP syndrome, severe pre-eclampsia, TTP, HUS and acute fatty liver of pregnancy) is not missed.

Monitoring of platelet count of mother should be a routine at antenatal visits for timely diagnosis and to achieve favourable obstetric outcome in all types of thrombocytopenia.

\section{ACKNOWLEDGMENTS}

Authors would like to thank all faculties colleague, post graduate residents and labour room staff for their support.

Funding: No funding sources

Conflict of interest: None declared

Ethical approval: The study was approved by the Institutional Ethics Committee

\section{REFERENCES}

1. Saino S, Kekomaki R, Riikonon S, Teramo $\mathrm{K}$. Maternal thrombocytopenia at term: a populationbased study. Acta Obstet Gynecol Scand. 2000;79(9):744-9.

2. Sullivan CA, Martin JN. Management of the obstetric patient with thrombocytopenia. Clin Obstet Gynecol. 1995;38:521-34. 
3. Burrows RF, Kelton JG. Thrombocytopenia at delivery: a prospective survey of 6715 deliveries. Am J Obstet Gynecol. 1990;162:731-4.

4. Gernsheimer T, James AH, Stasi R. How I treat thrombocytopenia in pregnancy. Blood. 2013;121(1):38-47.

5. Richard F, Alexandre H. Thrombocytopenia in pregnancy, 2006. Available at: www.emedicine.medscape.com/article. Accessed on $15^{\text {th }}$ January 2020.

6. Dwivedi P, Puri M, Nigam A, Agarwal K. Fetomaternal outcome in pregnancy with severe thrombocytopenia. Eur Rev Med Pharmacol Sci. 2012;16(11):1563-6.

7. Vyas R, Shah S, Yadav P, Patel U. Comparative study of mild versus moderate to severe thrombocytopenia in third trimester of pregnancy in a tertiary care hospital. NHL J Med Sci. 2014;3(1):811.

8. Burrows RF, Kelton JG. Thrombocytopenia at delivery: a prospective survey of 6715 deliveries. Am J Obstet Gynecol. 1990;162(3):731-4.

9. Singh N, Amita D, Uma S, Tripathi AK, Pushplata S. Prevalence and characterization of thrombocytopenia in pregnancy in Indian women. Indian $\mathbf{J}$ Hematol Blood Transfus. 2012;28(2):77-81.

10. Ajibola SO, Akinbami A, Rabiu K, Adewunmi A, Dosunmu A, Adewumi A. Gestational thrombocytopaenia among pregnant women in Lagos Nigeria. Niger Med J. 2014;55(2):139-43.

11. Onisai M, Vladareanu AM, Delcea C, Ciorascu M, Bumbea H, Nicolescu A. Perinatal outcome for pregnancies complicated with thrombocytopenia. J Matern Fetal Neonatal Med. 2012;25(9):1622-6.

12. Brohi ZP, Perveen U, Sadaf A. Thrombocytopenia in pregnancy: an observational study. Pak J Med. 2013;52(3):67-70.

13. Lin YH, Lo LM, Hsieh CC, Chiu TH, Hsieh TT, Hung TH. Perinatal outcome in normal pregnant women with incidental thrombocytopenia at delivery. Taiwan J Obstet Gynecol. 2013;52(3):347-50.

14. Suri V, Aggarwal N, Saxena S, Malhotra P, Varma S. Maternal and perinatal outcome in idiopathic thrombocytopenic purpura (ITP) with pregnancy. Acta Obstet Gynecol Scand. 2006;85(12):1430-5.

15. Borna $\mathrm{S}$, Borna $\mathrm{H}$, Khazardoost $\mathrm{S}$. Maternal and neonatal outcomes in pregnant women with immune thrombocytopenic purpura. Arch Iran Med. 2006;9(2):115-8.

16. Turgut A, Demirci O, Demirci E, Uludoğan $M$. Comparison of maternal and neonatal outcomes in women with HELLP syndrome and women with severe preeclampsia without HELLP syndrome. J Prenat Med. 2010;4(3):51-8.
17. Jaleel A, Baseer A. Thrombocytopenia in preeclampsia: an earlier detector of HELLP syndrome. J Pak Med Assoc. 1997;47(9):230-2.

18. Ruggeri M, Schiavotto C, Castaman G, Tosetto A, Rodeghiero F. Gestational thrombocytopenia: a prospective study. Haematol. 1997;82(3):341-2.

19. Janes SL. Thrombocytopenia in pregnancy. Postgrad Med J. 1992; 68:321-6.

20. Kasai J, Aoki S, Kamiya N, Hasegawa Y, Kurasawa $\mathrm{K}$, Takahashi T, et al. Clinical features of gestational thrombocytopenia difficult to differenciate from immune thrombocytopenia diagnosed during pregnancy. J Obstet Gynaecol Res. 2015;41(1):44-9.

21. Bouzari Z, Firoozabadi S, Hasannasab B, Emamimeybodi S, Golsorkhtabar-Amiri M. Maternal and neonatal outcomes in HELLP syndrome, partial HELLP syndrome and severe pre-eclampsia: eleven years' experience of an obstetric center in the North of Iran. World Applied Sci J. 2013;26(11):1459-63.

22. Parnas M, Sheiner E, Shoham-Vardi I, Burstein E, Yermiahu T, Levi I, et al. Moderate to severe thrombocytopenia during pregnancy. Eur J Obstet Gynecol Reprod Biol. 2006;128(1-2):163-8.

23. Turgut A, Demirci O, Demirci E, Uludoğan $M$. Comparison of maternal and neonatal outcomes in women with HELLP syndrome and women with severe preeclampsia without HELLP syndrome. J Prenat Med. 2010;4(3):51-8.

24. Habas E, Rayani A, Ganterie R. Thrombocytopenia in hypertensive disorders of pregnancy. J Obstet Gynaecol India. 2013;63(2):96-100.

25. Pafumi C, Valenti O, Giuffrida L, Colletta G. Gestational thrombocytopenia: does it cause any maternal and /or perinatal morbidity? Cukurova Med J. 2013;38(3):349-57.

26. Yuce T, Acar D, Kalafat E, Alkilic A, Cetindag E, Soylemez F. Thrombocytopenia in pregnancy: do the time of diagnosis and delivery route affect pregnancy outcome in parturients with idiopathic thrombocytopenic purpura? Int J Hematol. 2014;100(6):540-4.

27. Ajzenberg N, Dreyfus M, Kaplan C, Yvart J, Weill B, Tchernia G. Pregnancy associated thrombocytopenia revisited: assessment and followup of 50 cases. Blood. 1998;92(12):4573-80.

Cite this article as: Sojitra M, Shah SR, Mehta AV, Panchal PP. Maternal outcome in pregnancy with thrombocytopenia. Int J Reprod Contracept Obstet Gynecol 2020;9:2895-9. 